\title{
Características da Carcaça de Bezerros Holandeses para Produção de Vitelos Recebendo Dietas com Diferentes Níveis de Concentrado ${ }^{1}$
}

\author{
Telma Regina Ribeiro ${ }^{2}$, José Carlos Pereira ${ }^{3}$, Marcus Vinícius Morais de Oliveira ${ }^{4}$, \\ Augusto César de Queiroz ${ }^{3}$, Paulo Roberto Cecon ${ }^{5}$, Maria Ignez Leão ${ }^{3}$, \\ Rosana Coelho de Alvarenga e Melo4
}

\begin{abstract}
RESUMO - O experimento foi realizado utilizando 20 bezerros da raça Holandesa, machos não castrados, com o objetivo de avaliar as características das carcaças desses animais alimentados com dietas contendo 45, 60, 75 e $90 \%$ de concentrado. As dietas foram constituídas de feno de capim-coastcross, fubá de milho, farelo de soja e mistura mineral, fornecidas à vontade. O delineamento experimental foi em blocos casualizados, com quatro tratamentos e cinco repetições. Antes do início do experimento, todos os animais foram submetidos a um mesmo sistema de aleitamento. O período experimental foi variável para cada tratamento, em que os animais eram abatidos, após jejum de 16 horas, à medida que atingiam o peso vivo médio de $200 \mathrm{~kg}$. Nas meias carcaças esquerdas foram medidas a área de olho de lombo, o comprimento da carcaça e a sua composição física, enquanto nas meias carcaças direitas foram feitos os cortes básicos da carcaça. O rendimento das carcaças quente e fria com base no peso vivo dos animais, o rendimento da carcaça quente com base no peso corporal vazio e a área de olho de lombo dos animais apresentaram diferenças significativas com o acréscimo de concentrado nas dietas. Não houve diferenças significativas para peso vivo final, peso da carcaça quente, peso da carcaça fria e rendimento da carcaça fria com base no peso corporal vazio, assim como nas perdas de peso nas carcaças ocasionadas pelo tempo de jejum ao qual os animais foram submetidos antes do abate, nos cortes básicos e no rendimento do dianteiro e traseiro nas carcaças.
\end{abstract}

Palavras-chave: bezerros holandeses, carcaça, composição física, níveis de concentrado, vitelos

\section{Carcass Characteristics of Holstein Veal Calves Fed Diets with Different Levels of Concentrate}

\begin{abstract}
The experiment was carried out with 20 Holstein intact male calves to study the carcass characteristics of these animals fed with diets containing 45, 60, 75 and $90 \%$ of concentrate. Diets were composed of coastcross hay, ground corn grain, soybean meal and mineral mixture fed ad libitum. A completely randomized blocks experimental design, with four treatments and five replications, was used. Before the beginning of the experiment, all animals were submitted to the same nursing system. The experimental period was different for each treatment, since the animals were slaughtered as they reached the average live weight of $200 \mathrm{~kg}$. Before the slaughter, the animals were fasted for 16 hours. The left half carcasses were used to measure the loin eye area, length of carcass and their physical composition, and on the right half carcasses the basic cuts were made. The hot and cold carcass yields based on the live weight of the animals and the hot carcass yield based on the empty body weight and the loin eye area showed differences as the levels of concentrate in the diets increased. There were no significant differences for final live weight, hot carcass weight, cold carcass weight, cold carcass dressing based on the empty body weight, neither regarding the losses of weight of carcasses caused by the fasting period before slaughter, nor the basic cuts and nor the fore and hind quarter dressing.
\end{abstract}

Key Words: carcass, Holstein calves, levels of concentrate, physical composition, veal calves

\section{Introdução}

Apesar de o Brasil ser detentor de um dos maiores rebanhos de bovinos do mundo, o seu volume de exportações ainda é inexpressivo, além de não atender de forma adequada a demanda interna. Entre os diversos fatores relacionados a este fato, destacam-se a baixa produtividade de seu rebanho, a falta de estímulo aos produtores, no sentido de uma remuneração condizente com os animais que apresentem melhores carcaças, além de problemas sanitários no rebanho.

Diante destes fatos, surge a necessidade de aumentar a produção total de carne no país. Para isso, não só devem ser criadas condições para que o produtor possa realizar investimentos, a fim de me-

\footnotetext{
${ }^{1}$ Parte da tese apresentada à UFV, pelo segundo autor, para obtenção do título de Mestre em Zootecnia, financiada pelo CNPq.

2 Eng ${ }^{\circ}$-Agr ${ }^{\circ}$, MS em Zootecnia.

${ }^{3}$ Professores do DZO/Universidade Federal de Viçosa, Bolsistas do CNPq.

4 Zootecnista, Estudantes de Doutorado do DZO/UFV e DEA/UFV. E.mail: ds16672@correio.ufv.br; zana@dea.ufv.br

5 Professor do DPI/UFV.
} 
lhorar a produtividade de seu rebanho, mas também cumpre verificar a possibilidade de aproveitamento dos bezerros provenientes de raças produtoras de leite, para o abate (DODE et al., 1986). Nesse sentido, com o crescimento da exploração leiteira no Brasil, aumentam-se as chances de se aproveitarem os machos para produção de carne, os quais normalmente são sacrificados ao nascer, ou vendidos para fins industriais. Todavia, o sistema de produção de animais precoces é um desafio, devido às elevadas exigências nutricionais apresentadas, por causa da alta deposição de músculos e do crescimento dos ossos (LANNA, 1997). Desse modo, é necessário utilizar dietas com elevada densidade energética e proteica, para poder alcançar o peso de carcaça ideal e a quantidade mínima de gordura de cobertura (RESTLE, 1997).

De acordo com KEMPSTER e SOUTHGATE (1984), cerca de $40 \%$ da carne produzida na Inglaterra era proveniente de bezerros holandeses e mestiços holandeses com raças de corte e, nos Estados Unidos, em torno de $70 \%$ dos machos provenientes de rebanhos leiteiros são destinados à produção de vitelos, os quais são divididos em classes, de acordo com o peso de abate e tipo de alimento usado, alimentação líquida exclusiva ou sua combinação com alimentos sólidos (USDA, 1995), o que influi sobre a coloração da carcaça e, por conseqüência, sobre o preço do produto.

Na Europa, adota-se um sistema com alimentação líquida, à base de sucedâneos do leite, para produzir o vitelo de carne branca, abatido aos 3-5 meses, e peso de carcaça da ordem de $70-125 \mathrm{~kg}$; e o vitelo de carne rosada, que recebe ainda alimentos sólidos, abatido aos 5-6 meses de idade, com carcaças pesando entre 135-150 kg (PEREZ REDONDO, 1991).

O objetivo do estudo das carcaças é a avaliação de parâmetros diretamente relacionados aos aspectos qualitativos e quantitativos de sua porção comestível (GALVÃO et al., 1991), sendo que as características que influenciam ou determinam a qualidade e os rendimentos são de extrema importância para pecuaristas e indústrias de carne; por essa razão, têm sido exaustivamente estudadas (LUCHIARI FILHO e ALLEN, 1982).

O rendimento da carcaça está sujeito a variações por influência de fatores como sistema de cálculo (em relação ao peso vivo ou peso corporal vazio), número de horas de jejum, dieta imposta aos animais, peso de abate, grau de engorda, entre outros fatores (GALVÃO et al., 1991). Resultados mais consisten- tes são obtidos, quando é calculado em relação ao peso corporal vazio, uma vez que o peso do conteúdo gastrintestinal varia amplamente (de 10 a $20 \%$ do peso vivo), em função do sistema de alimentação, da idade do animal e do tempo decorrido da última refeição (Geay, 1975, citado por PERON, 1991). No caso de se utilizar o peso vivo, o rendimento é afetado pelo número de horas de jejum e tipo de dieta (FIELD e SCHOONOVER, 1967; PRESTON e WILLIS, 1974; PERON, 1991).

Economicamente, é desejável maior rendimento do traseiro, uma vez que nele se encontram as partes nobres da carcaça, que alcançam maior valor comercial, e o conhecimento da composição física da carcaça expressa, normalmente, em termos de porcentagem de músculo, tecido adiposo e ossos, é de interesse na comparação de grupos genéticos, fontes e níveis nutricionais.

Em condições normais e independentemente da raça, o animal tende a apresentar equilíbrio entre os quartos traseiro e dianteiro (BERG e BUTTERFIELD, 1979).

Objetivou-se, neste estudo, avaliar as características das carcaças de bezerros holandeses alimentados com dietas contendo diferentes níveis de concentrado, em sistema de produção de vitelos.

\section{Material e Métodos}

Foram utilizados 20 bezerros holandeses puros por cruza (HPC), machos não-castrados, com idade aproximada de 75 dias e peso médio de $76 \mathrm{~kg}$, mantidos em regime de confinamento, em baias individuais cobertas de $8 \mathrm{~m}^{2}$, com piso concretado, providas de comedouro e bebedouro.

Do nascimento até o início do experimento, os animais foram submetidos a um único sistema de aleitamento, que consistiu de quatro litros de uma mistura preparada com sucedâneo comercial do leite, fornecidos duas vezes ao dia, durante 60 dias. Todos os animais durante esse período tiveram acesso a volumoso - feno de capim coastcross (Cynodon dactylon (L.) Pers.) picado - e ração concentrada à vontade.

Os 20 animais foram sorteados aleatoriamente, em cinco blocos com quatro animais cada, distribuídos ao acaso entre quatro tratamentos, que compreenderam quatro níveis de concentrado na dieta.

O período de adaptação às instalações e ao sistema de manejo empregado teve duração de 15 dias, durante o qual todos os animais receberam a ração utilizada no período experimental à vontade; além de receberem

Rev. bras. zootec., 30(6S):2154-2162, 2001 
vitamina A injetável, foram tratados contra endo e ectoparasitas, pesados e identificados.

O período experimental foi variável para cada tratamento, por conseguinte, não teve duração préfixada, posto que os animais eram abatidos à medida que atingiam o peso médio de $200 \mathrm{~kg}$, estabelecido em função do sistema de produção proposto para o trabalho.

As dietas eram fornecidas, à vontade, uma vez ao dia, pela manhã, e calculadas com base nas exigências nutricionais estabelecidas pelo NRC (1988), para um ganho de peso esperado de $1,0 \mathrm{~kg}$ diário. A constituição das dietas e os ingredientes e respectivas composições são apresentados nas Tabelas 1, 2 e 3.

Foram feitas pesagens a cada 28 dias e, à medida que os animais de cada baia atingiam o peso vivo médio de $200 \mathrm{~kg}$, eram abatidos, sendo submetidos a um período de jejum alimentar prévio de cerca de 16 horas, mas com livre acesso à água. Imediatamente, antes do abate, cada animal era pesado, obtendo-se seu peso vivo final (PVF). Após o abate, removeu-se e pesou-se o trato gastrintestinal cheio, que, a seguir, foi esvaziado e lavado. Realizado o escorrimento da água de lavagem, pesava-se novamente o trato gastrintestinal, obtendo-se, assim, seu peso vazio. Deduzindo-se o peso do trato gastrintestinal vazio do peso cheio, obtinha-se o peso do conteúdo do trato gastrintestinal, que era subtraído do peso vivo final para

Tabela 1 - Composição percentual dos ingredientes das rações (base da matéria seca)

Table 1 - Percentage composition of ingredients in the diets (dry matter basis)

\begin{tabular}{lcccc}
\hline $\begin{array}{l}\text { Ingredientes } \\
\text { Ingredients }\end{array}$ & \multicolumn{4}{c}{$\begin{array}{c}\text { Rações } \\
\text { Diets }\end{array}$} \\
\cline { 2 - 5 } & 45 & 60 & 75 & 90 \\
\hline $\begin{array}{l}\text { Feno coastcross } \\
\text { Coastcross hay }\end{array}$ & 54,10 & 38,80 & 23,49 & 8,20 \\
$\begin{array}{l}\text { Fubá de milho } \\
\begin{array}{l}\text { Ground corn grain } \\
\text { Farelo de soja }\end{array}\end{array}$ & 24,44 & 41,20 & 57,97 & 74,49 \\
$\begin{array}{l}\text { Soybean meal } \\
\text { Mistura mineral }\end{array}$ & 20,56 & 18,80 & 17,04 & 15,51 \\
$\begin{array}{l}\text { Mineral mixture } \\
\text { Calcário }\end{array}$ & 0,45 & 0,60 & 0,75 & 0,90 \\
\begin{tabular}{l} 
Limestone \\
\hline
\end{tabular} & 0,45 & 0,60 & 0,75 & 0,90 \\
\hline
\end{tabular}

${ }^{1}$ Mistura mineral contendo em cada kg: $420 \mathrm{~g}$ de fosfato bicálcico, $54 \mathrm{~g}$ de calcário calcítico; $519,12 \mathrm{~g}$ de cloreto de sódio; $2,0 \mathrm{~g}$ de sulfato de cobre; $4 \mathrm{~g}$ de óxido de zinco; $0,3 \mathrm{~g}$ de iodato de cálcio; $0,5 \mathrm{~g}$ de sulfato de cobalto e $0,8 \mathrm{~g}$ selenito de sódio.

${ }^{1}$ Mineral mix contents per $\mathrm{kg}: 420 \mathrm{~g}$ of dicalcium phosphate; $54 \mathrm{~g}$ of limestone; $519.12 \mathrm{~g}$ of sodium chloride; $2.0 \mathrm{~g}$ of cooper sulphate; $4.0 \mathrm{~g}$ of zinc oxide; $0.3 \mathrm{~g}$ of calcium iodate; $0.5 \mathrm{~g}$ of cobalt sulphate and $0.8 \mathrm{~g}$ of sodium selenite.

Rev. bras. zootec., 30(6S):2154-2162, 2001

Rev. bras. zootec, 30(6S):2154-2162, 2001
Tabela 2 - Teores de matéria seca (MS), proteína bruta (PB) e fibra em detergente neutro (FDN) das rações experimentais

Table 2 - Dry matter (DM), crude protein (CP) and neutral detergent fiber (NDF) contents in the experimental diets

\begin{tabular}{lcccc}
\hline & \multicolumn{4}{c}{ Rações } \\
& \multicolumn{4}{c}{ Diets } \\
\cline { 2 - 5 } $\begin{array}{l}\text { Nutrientes } \\
\text { Nutrients }\end{array}$ & 45 & 60 & 75 & 90 \\
\hline MS $(D M)$ & & & & \\
PB $(C P)$ & 86,99 & 86,60 & 86,21 & 85,83 \\
FDN $(N D F)$ & 16,39 & 15,99 & 15,57 & 15,26 \\
\hline
\end{tabular}

se obter o peso de corpo vazio (PCVZ) de cada animal.

A carcaça era dividida em duas metades, e estas eram pesadas individualmente. Com base nas informações coletadas, foram calculados os valores de rendimento de carcaça, em função do peso vivo (RCQ) e peso de corpo vazio (RCQCVZ), e ganho de peso vivo (GPV) e peso de corpo vazio (GPCVZ). Em seguida, as duas metades da carcaça eram levadas à câmara fria, onde permaneciam por, aproximadamente, 18 horas, à temperatura de $-5^{\circ} \mathrm{C}$. Decorrido esse tempo, pesaram-se as meias carcaças resfriadas para determinar seu rendimento após o resfriamento (RCF), seu rendimento em função do peso de corpo vazio (RCFCVZ) e, ainda, o comprimento da carcaça (CC) partindo-se da porção mediana anterior da $1^{\mathrm{a}}$ costela até o ponto mediano da curvatura do osso do púbis. A partir da metade esquerda da carcaça, retiravam-se as seções transversais, em sua totalidade, as quais incluíam as $9^{\mathrm{a}}, 10^{\mathrm{a}}$ e $11^{\mathrm{a}}$ costelas, a partir da qual se destacava a seção correspondente $\mathrm{H} \& \mathrm{H}$, segundo HANSKINS e HOWE (1946). Nas seções retiradas da carcaça, determinaram-se as proporções de músculo, tecido adiposo e ossos.

Também na meia carcaça esquerda, mediu-se a área de olho do músculo Longissimus dorsi (AOL) à altura da $12^{\mathrm{a}}$ costela.

As meias carcaças direitas resfriadas foram utilizadas para determinação de rendimento de dianteiro com cinco costelas, traseiro (oito costelas), traseiro especial e cortes primários - coxão, ponta de agulha completa, alcatra completa, acém completo e paleta completa.

Para a análise das variáveis de rendimento de cortes básicos e composição física da carcaça, foi utilizado o delineamento em blocos casualizados, com quatro tratamentos e cinco repetições. Os dados foram interpretados por meio de análise de variância 
Tabela 3 - Teores de matéria seca (MS), proteína bruta (PB) e fibra em detergente neutro (FDN) dos ingredientes das rações experimentais

Table 3 - Drymatter(DM), crude protein (CP) and neutral detergent fiber (NDF) contents of the ingredients of the experimental diets

\begin{tabular}{lccc}
\hline $\begin{array}{l}\text { Ingredientes } \\
\text { Ingredients }\end{array}$ & $\begin{array}{c}\text { MS (\%) } \\
D M(\%)\end{array}$ & $\begin{array}{c}\text { PB }(\% \mathrm{MS}) \\
C P(\% D M)\end{array}$ & $\begin{array}{c}\text { FDN }(\% \mathrm{MS}) \\
N D F(\% D M)\end{array}$ \\
\hline $\begin{array}{l}\text { Feno de coastcross } \\
\begin{array}{l}\text { Coastcross hay } \\
\text { Fubá de milho } \\
\text { Ground corn grain }\end{array}\end{array}$ & 88,22 & 6,77 & 83,40 \\
$\begin{array}{l}\text { Farelo de soja } \\
\text { Soybean meal }\end{array}$ & 87,08 & 51,13 & 12,10 \\
\hline
\end{tabular}

e regressão. Os modelos foram escolhidos com base na significância dos coeficientes de regressão, pelo teste " $t$ " de Student a 5\%, pelo coeficiente de determinação, utilizando-se o programa SAEG (Sistema de Análises Estatísticas e Genéticas), conforme UNIVERSIDADE FEDERAL DE VIÇOSA - UFV (1995).

O modelo matemático utilizado foi:

$$
\mathrm{Y}_{\mathrm{ij}}=\mu+\mathrm{b}_{\mathrm{j}}+\mathrm{t}_{\mathrm{i}}+\mathrm{e}_{\mathrm{ij}}
$$

em que: $Y_{i j}=$ variável observada em questão, no tratamento $i$, no bloco $j ; \mu=$ média geral; $b_{j}=$ efeito do bloco $\mathrm{j}$, sendo $\mathrm{j}=1,2, . ., 5 ; \mathrm{t}_{\mathrm{i}}=$ efeito do tratamento $\mathrm{i}$, sendo $\mathrm{i}=$ níveis de concentrado nas dietas $(45,60$, $75,90) ; \mathrm{e}_{\mathrm{ij}}=$ erro aleatório.

\section{Resultados e Discussão}

Como pode ser verificado na Figura 1, os resultados do peso vivo final e o peso em jejum, por ocasião do abate dos animais, mantiveram-se constantes, uma vez que o peso médio de abate e o tempo de jejum dos animais já haviam sido estabelecidos para todos os animais do experimento.

Constam da Figura 2 as equações de regressão e seus respectivos coeficientes de determinação do ganho de peso e ganho de peso do corpo vazio, em função dos níveis de concentrado.

O rendimento de carcaça, muitas vezes, não dá boa idéia do rendimento de carne aproveitável. No caso de animais gordos, a gordura tem efeito de diluir a proporção de músculos e, quando seu excesso é eliminado, reduz-se a fração aproveitável (GALVÃO et al., 1991); da mesma forma, o peso da cabeça, couro e trato gastrintestinal também têm influência direta (PERON, 1991).

Rev. bras. zootec., 30(6S):2154-2162, 2001
A análise de variância dos dados de rendimento de carcaça quente (RCQ) e fria (RCF) mostrou efeito significativo $(\mathrm{P}<0,05)$ dos níveis de concentrado nas dietas.

A análise de regressão mostrou aumento linear do RCQ $(\mathrm{P}<0,01)$ e RCF $(\mathrm{P}<0,05)$ com a elevação dos níveis de concentrado das dietas (Figura 3 ).

O aumento observado no rendimento de carcaça, quente e fria, é em virtude de os animais alimentados com $90 \%$ de concentrado apresentarem peso do conteúdo gastrintestinal menor que aqueles que receberam rações com níveis mais baixos de concentrado.

Os rendimentos de carcaça quente $(\mathrm{P}<0,01)$ e fria $(\mathrm{P}<0,05)$, com base no peso de corpo vazio, foram influenciados pelos níveis de concentrado da dieta, como pode ser observado na Figura 4.

Como pode ser verificado, os animais alimentados com $45 \%$ de concentrado apresentaram maiores rendimentos de carcaça quente, com base no peso de corpo vazio, o que pode ser explicado pelo fato de que esses animais apresentaram maiores proporções de músculos em suas carcaças e menores tamanhos relativos dos órgãos em comparação aos animais alimentados com $90 \%$ de concentrado.

VELLOSO et al. (1975) observaram rendimento de carcaça de 51,5 e $50,4 \%$ para animais holandeses inteiros e castrados, respectivamente, e menor espessura de gordura em animais inteiros.

As maiores quebras no peso das carcaças, observadas durante o resfriamento (PRESF), para os ani-

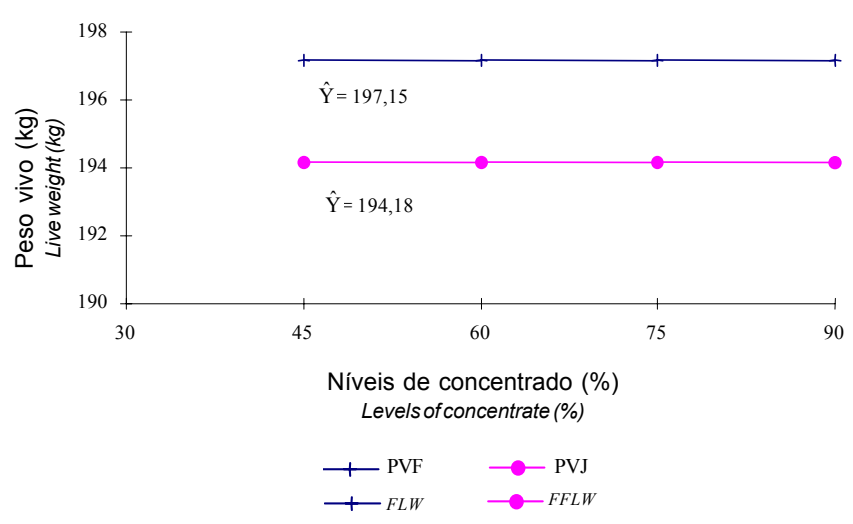

Figura 1 - Estimativa do peso vivo final (PVF) e peso vivo final de jejum (PVJ) dos animais, em função dos níveis de concentrado nas dietas.

Figure 1 - Estimate of the final live weight (FLW) and final live weight fast (FLWF) of the animals, in relation to the levels of concentrate in the diets. 


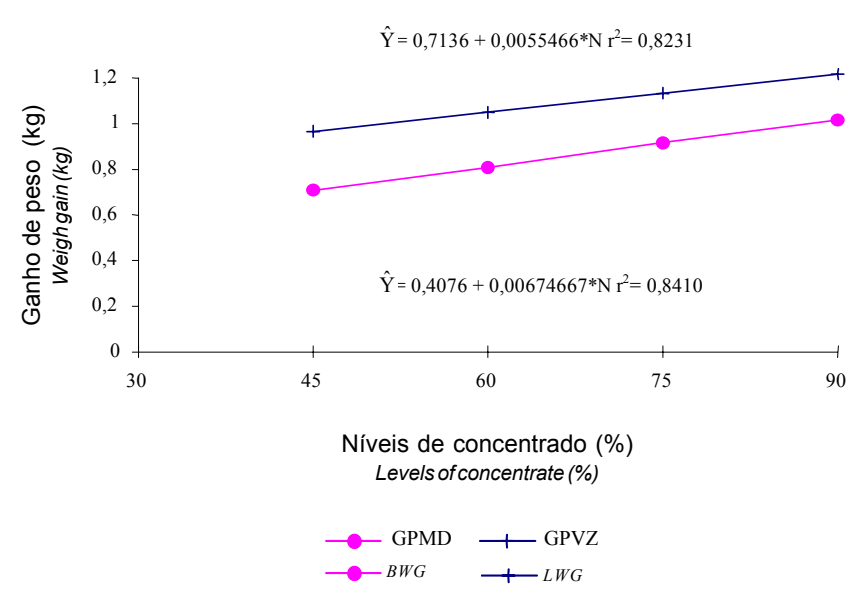

Figura 2 - Estimativa doganho de pesovivomédio diário(GPMD) e ganho de peso de corpo vazio (GPVZ) dos animais, em função dos níveis de concentrado nas dietas.

Figure 2 - Estimate of daily live weight gain (LWG), and empty body weight gain (EWG) of the animals, in relation to the levels of concentrate in the diets.

mais alimentados com níveis mais baixos de concentrado, estão relacionadas à ausência de gordura de cobertura. Certa quantidade de gordura é desejável, pois a mesma tem a função de proteger as carcaças contra o ressecamento causado pelo resfriamento; fato que ocorreu com as carcaças dos animais alimentados com $90 \%$ de concentrado. Isso explica também a constância nos dados para o rendimento de carcaça fria, com base no peso de corpo vazio para todos os níveis de concentrado estudados.

Segundo MARTINS (1997), o percentual de perda no resfriamento indica as perdas ocorridas em função de alguns fatores, como perda de umidade e reações químicas que ocorrem no músculo. Assim, quanto menor este percentual, maior é a probabilidade da carcaça ter sido manejada e armazenada de modo adequado. O percentual de perda encontrado foi relativamente alto, sendo verificadas diferenças $(\mathrm{P}<0,05)$ entre as dietas, de modo que o melhor índice foi para o tratamento com $75 \%$ de concentrado. No entanto, esta perda poderia ser menor, se os animais tivessem sido abatidos com maior peso, de modo que apresentassem maior camada de gordura de cobertura, já que a mesma tem função de proteger a carcaça contra o ressecamento causado pelo frio. Porém, o sistema de produção de vitelos implica em obter carcaças com baixos níveis de gordura.

Rev. bras. zootec., 30(6S):2154-2162, 2001

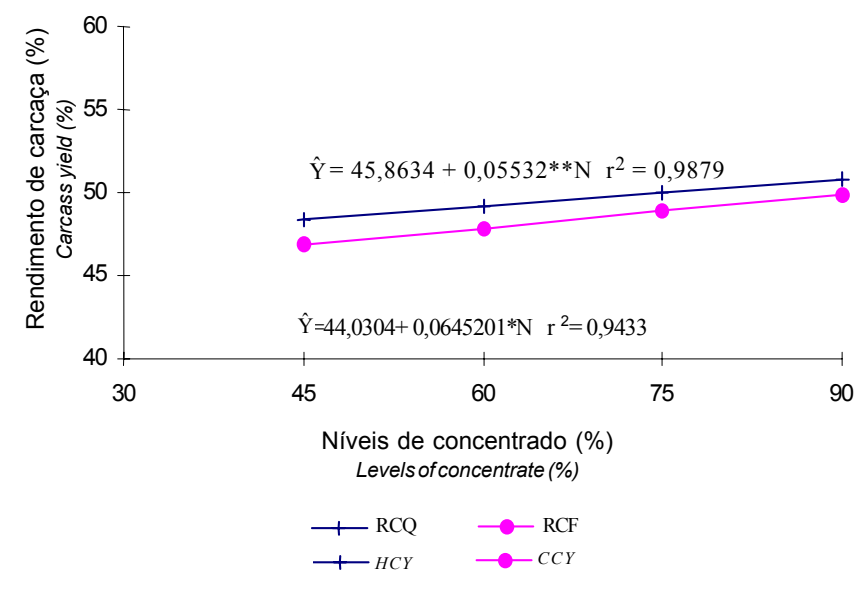

Figura 3 - Estimativa do rendimento de carcaça quente (RCQ) e fria (RCF), com base no peso vivo dos animais, em função dos níveis de concentrado nas dietas

Figure 3 - Estimate of hot carcass yield ( $\mathrm{HCY}$ ) and cold carcass yield (CCY), based on the live weight of the animals, in relation to the levels of concentrate in the diets.

$\mathrm{Na}$ Tabela 4 são apresentados os valores médios dos pesos das carcaças quente (PCQ) e carcaça fria (PCF), rendimento da carcaça fria em função do peso de corpo vazio (RCFCZ), e comprimento da carcaça (CCARC), que se mostraram constantes para os níveis de concentrado nas dietas.

Os níveis de concentrado nas dietas não influenciaram $(\mathrm{P}>0,05)$ os pesos das carcaças quentes (PCQ)

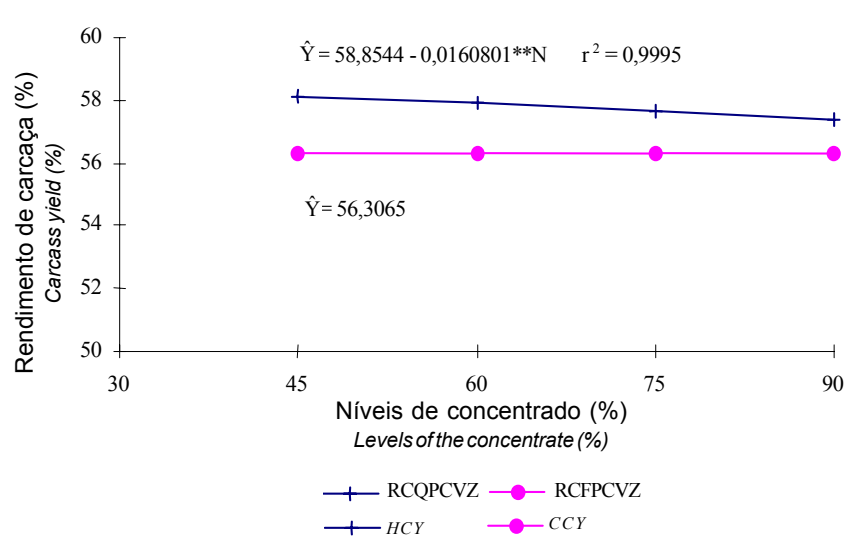

Figura 4 - Estimativa do rendimento de carcaça quente (RCQCVZ) e fria (RCFCVZ), com base no peso de corpo vazio, em função dos níveis de concentrado nas dietas.

Figure 4 - Estimate of hot carcass yield (HCY) and cold carcass yield (CCY), based on the empty body weight in relation to the levels of concentrate in the diets. 


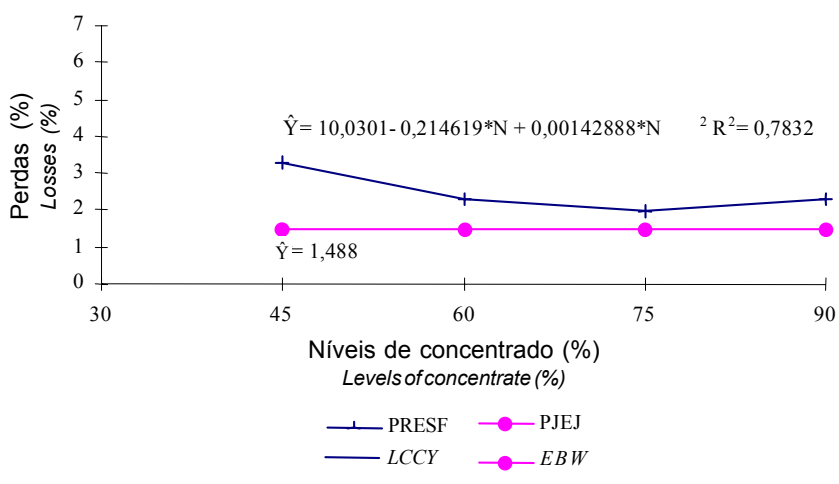

Figura 5 - Estimativa das perdas no rendimento da carcaça fria em relação ao peso vivo (PRESF) e ao peso de corpo vazio (PJEJ), em função dos níveis de concentrado nas dietas.

Figure 5 - Estimate of the losses in the cold carcass yield according to live weight (LCCY) and empty body weight (EBW), in relation to the levels of concentrate in the diets.
Tabela 4 - Médias do peso da carcaça quente (PCQ), peso da carcaça fria (PCF), rendimento da carcaça fria em função do peso de corpo vazio (RCFPCZ), e comprimento da carcaça (CC), em função dos níveis de concentrado nas dietas

Table 4 - Hot carcass weight (HCW), cold carcass weight (CCW), cold carcass yield average according to empty body weight (CCYEBW), and length of carcass (LC), in relation to the levels of concentrate in the diets

Níveis de concentrado nas dietas Levels of concentrate in the diets

\begin{tabular}{lccccc} 
Parâmetros & 45 & 60 & 75 & 90 & $\begin{array}{c}\text { Média } \\
\text { Parameters }\end{array}$ \\
\cline { 2 - 5 } & & & 95,90 & 98,30 & 96,30 \\
\hline $\begin{array}{l}\text { PCQ }(\mathrm{kg}) \\
\text { HOW }\end{array}$ & 93,22 & 97,80 & 95,90 & \\
PCF $(\mathrm{kg})$ & 90,10 & 95,90 & 93,60 & 96,20 & 93,95 \\
$\begin{array}{l}C C W \\
\text { RCFPCZ }(\%)\end{array}$ & 55,98 & 56,80 & 56,30 & 56,20 & 56,32 \\
$\begin{array}{l}C C Y E B W \\
\text { CC }(\mathrm{cm})\end{array}$ & 102,00 & 103,30 & 104,20 & 103,40 & 103,30 \\
$L C$ & & & & & \\
\hline
\end{tabular}

e fria (PCF), uma vez que os pesos médios para o abate e o tempo de jejum dos animais foram fixados previamente.

Na Figura 6 é mostrado o desenvolvimento da AOL, em função dos níveis de concentrado.

A área de olho de lombo (AOL), medida normalmente na seção transversal do músculo Longissimus dorsi entre a $12^{\mathrm{a}}$ e $13^{\mathrm{a}}$ costelas, é normalmente considerada, no estudo de carcaça, indicador de desenvolvimento muscular fisicamente separável da carcaça (GALVÃo et al., 1991).

Avaliando a área de olho de lombo, como indicador único da musculosidade, PERON (1991) encontrou baixa correlação entre esta e a proporção de músculos na carcaça. Esses resultados confirmam observações de BERG E BUTTERFIELD (1979).

Ainda de acordo com MULLER(1980), a área de olho de lombo, isoladamente não representa alta correlação com a proporção de músculo na carcaça, mas, se utilizada em conjunto com outras características, pode auxiliar na avaliação do grau de rendimento dos cortes desossados na carcaça. Neste experimento, houve aumento linear $(\mathrm{P}<0,05)$ da área de olho de lombo com a elevação do nível de concentrado nas dietas, indicando que a energia adicional foi utilizada para deposição muscular, pois, por ocasião do abate, os animais apresentavam pouca ou nenhuma deposição de gordura de cobertura.

Os cortes básicos das carcaças de bovinos no mercado brasileiro resumem-se em dianteiro, con- tendo cinco costelas, que compreende o acém e a paleta completos e costilhar ou ponta de agulha e traseiro especial ou serrote, compreendendo o coxão, e a alcatra completa. Segundo PERON (1991), certos cuidados devem ser tomados quando se comparam os rendimentos desses cortes em diferentes animais, pois a divisão de certos cortes é feita de forma subjetiva, podendo, algumas vezes, levar a resultados distorcidos, como é o caso dos limites dos cortes costilhar e traseiro especial - que devem variar em função do tamanho dos animais, pois, caso seus ajustes sejam inadequados, podem causar variações nos rendimentos desses cortes.

As análises de variância, para rendimento e peso dos cortes das carcaças, não mostraram efeito significativo $(\mathrm{P}>0,05)$ do nível de concentrado nas dietas.

Como pode ser observado na Tabela 5 , não houve diferença $(\mathrm{P}>0,05)$ entre os níveis de concentrado estudados, em relação à porcentagem de dianteiro $\mathrm{e}$ traseiro, bem como para o peso absoluto da paleta, acém, ponta de agulha, coxão e alcatra.

A inexistência de diferença entre tratamentos pode ser atribuída ao grau de desenvolvimento semelhante dos animais nos diferentes tratamentos, já que todos foram abatidos com o mesmo peso médio.

JORGE (1993) relata que os animais, durante seu crescimento, tendem a manter certo equilíbrio quanto ao desenvolvimento das partes traseiras e dianteiras, além disso, há verifica-se uniformidade muito alta no desenvolvimento relativo dos músculos do corpo de

Rev. bras. zootec., 30(6S):2154-2162, 2001 


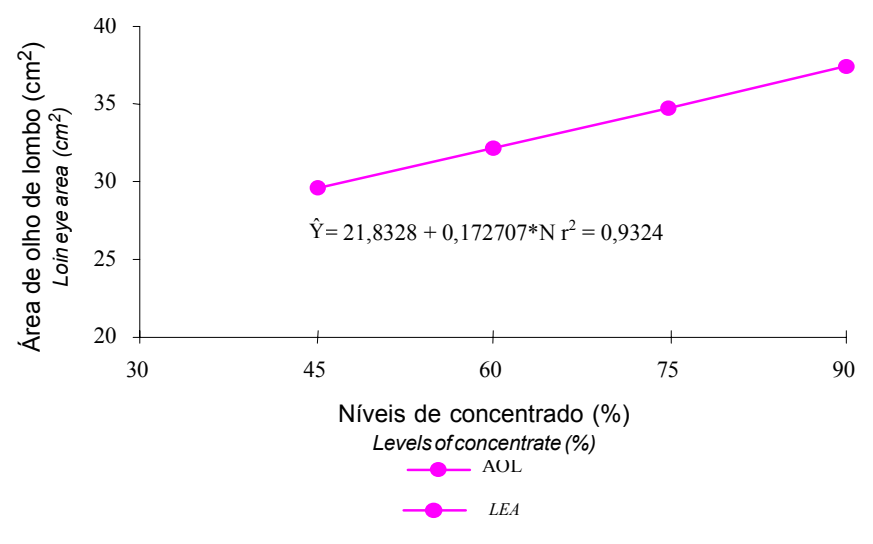

Figura 6 - Estimativa da área de olho de lombo (AOL) dos animais, em função dos níveis de concentrado nas dietas.

Figure 6 - Estimate of loin eye area (LEA) of the animals, in relation to the levels of concentrate in the diets.

bezerros submetidos a planos de nutrição alto, moderado e baixo (Butterfield e Johnson, 1971, citados por BERG e BUTTERFIELD, 1979).

As pequenas diferenças nos dados descritos podem estar relacionadas à variação na posição dos diversos cortes realizados nas carcaças, visto que todos os animais tendem a apresentar equilíbrio entre as várias partes de seu corpo, ou seja, o animal que apresenta maior peso da parte posterior do corpo tende a apresentar, igualmente, maior peso da parte anterior, mantendo-se constantes as proporções entre os cortes (BERG e BUTTERFIELD, 1979; TEIXEIRA, 1984; GONÇALVES, 1988; PERON, 1991; GALVÃO et al., 1991).

A análise de regressão indicou efeito quadrático $(\mathrm{P}<0,05)$ dos níveis de concentrado da ração sobre o rendimento de paleta (RPAL) e acém (RACEM). Estes efeitos podem ser observados na Figura 7, que mostra os valores estimados e calculados pelas equações.

As análises de variância para a proporção de músculo, tecido adiposo e ossos na SECHH mostraram efeito significativo $(\mathrm{P}<0,05)$ somente para a quantidade de músculo e gordura na carcaça dos animais.

As proporções de músculos, gordura e ossos na carcaça, estimadas com base nos valores obtidos na SECHH, utilizando-se as equações propostas por HANSKINS E HOWE (1946), podem ser observadas na Figura 8. Os animais alimentados com maiores níveis de concentrado apresentaram maior $(\mathrm{P}<0,05)$ porcentagem de gordura na carcaça e, conseqüentemente, menor $(\mathrm{P}<0,10)$ porcentagem de músculos, quando comparados aos animais alimentados com $45 \%$ de concentrado em suas dietas.

Os resultados acima descritos estão de acordo com aqueles encontrados por BOND et al. (1972) e JONES et al. (1985), que encontraram carcaças com maior quantidade de gordura para os animais alimentados com dietas à base de concentrado, quando comparados a animais que receberam dietas à base de feno.

Quanto à porcentagem de ossos na carcaça, embora houvesse tendência de maior proporção em animais alimentados com $75 \%$ de concentrado, não houve diferença entre os níveis de concentrado estudados, o que está de acordo com Long (1973), citado por GALVÃO et al. (1991), os quais afirmaram que o tecido ósseo apresenta pequena variação entre animais, e com BERG e BUTTERFIELD (1979), que afirmam ter o tecido ósseo maior impulso para o

Tabela 5 - Pesos absolutos médios da paleta (PAL), acém $(A C)$, ponta de agulha (PAGU), alcatra (ALC), coxão (COX) e rendimento de traseiro (RTRAS) e dianteiro (RDIANT), rendimento de ponta de agulha (RPAGU), alcatra (RALC) e coxão (RCOX), em função dos níveis de concentrado nas dietas

Table 5 - Absolute weight average of the whole shoulder-blade $(S B)$, chuck $(C)$, spare ribs (SR), rump (RU), round $(R D)$, and the hindquarter yield (HQY), forequarter yield (FQY), whole spare ribs yield (SRY), rump yield(RMY) and whole round yield (RY) in relation to the levels of concentrate in the diets

\begin{tabular}{|c|c|c|c|c|c|c|}
\hline \multirow[b]{2}{*}{$\begin{array}{l}\text { Parâmetros } \\
\text { Parameters }\end{array}$} & \multicolumn{6}{|c|}{$\begin{array}{l}\text { Níveis de concentrado nas dietas } \\
\text { Levels of concentrate in the diets }\end{array}$} \\
\hline & $\begin{array}{l}\text { Unidade } \\
\text { Unit }\end{array}$ & 45 & 60 & 75 & 90 & $\begin{array}{l}\text { Média } \\
\text { Mean }\end{array}$ \\
\hline $\begin{array}{l}\mathrm{PAL} \\
S B\end{array}$ & $\mathrm{~kg}$ & 8,45 & 8,98 & 8,67 & 9,53 & 8,96 \\
\hline $\begin{array}{l}\mathrm{AC} \\
C\end{array}$ & $\mathrm{~kg}$ & 9,38 & 9,49 & 9,06 & 9,23 & 9,29 \\
\hline $\begin{array}{l}\text { PAGU } \\
S R\end{array}$ & $\mathrm{~kg}$ & 4,39 & 5,28 & 4,98 & 5,04 & 4,92 \\
\hline $\begin{array}{l}\text { ALC } \\
R U\end{array}$ & $\mathrm{~kg}$ & 9,24 & 9,76 & 9,32 & 9,60 & 9,48 \\
\hline $\begin{array}{l}\mathrm{COX} \\
R D\end{array}$ & $\mathrm{~kg}$ & 14,24 & 14,94 & 14,58 & 14,63 & 14,6 \\
\hline $\begin{array}{l}\text { RTRAS } \\
H Q Y\end{array}$ & $\%$ & 60,92 & 61,89 & 61,96 & 60,90 & 61,41 \\
\hline $\begin{array}{l}\text { RDIANT } \\
F Q Y\end{array}$ & $\%$ & 39,08 & 38,11 & 38,04 & 39,10 & 38,63 \\
\hline $\begin{array}{l}\text { RPAGU } \\
S R Y\end{array}$ & $(\%)$ & 9,59 & 10,89 & 10,67 & 10,47 & 10,41 \\
\hline $\begin{array}{l}\text { RALC } \\
R M Y\end{array}$ & $(\%)$ & 20,17 & 20,13 & 20,02 & 19,98 & 20,08 \\
\hline $\begin{array}{l}\text { RCOX } \\
R Y\end{array}$ & $(\%)$ & 31,16 & 30,87 & 31,27 & 30,45 & 30,94 \\
\hline
\end{tabular}




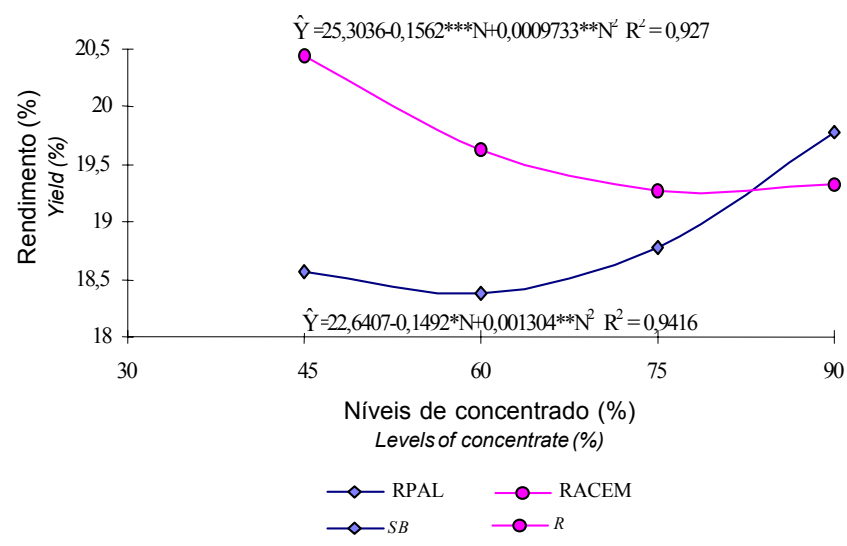

Figura 7 - Estimativa do rendimento de paleta (RPAL) e acém (RACEM), em função dos níveis de concentrado nas dietas.

Figure 7 - Estimate of the whole shoulder yield (SB) and whole chuck yield $(R)$, in relation to the levels of concentrate in the diets.

crescimento em idade mais precoce, enquanto o tecido adiposo tem crescimento em idade mais tardia que o tecido muscular intermediário.

Segundo Cole et al. (1962), citados por JORGE (1993), é desaconselhável, em razão de erros que possam surgir, comparar animais precoces, cujo acúmulo de gordura subcutânea é bem mais acentuado, com animais tardios, que apresentam menor quantidade absoluta de gordura subcutânea e baixa variabilidade em sua espessura, fato que ocorre quando abate se dá a um mesmo peso vivo.

Não houve efeito $(\mathrm{P}>0,05)$ de nível de concentrado sobre as proporções de músculo e ossos na carcaça, embora se tenha observado tendência de menor quantidade de músculo em animais alimentados com dietas contendo $75 \%$ de concentrado, devido à sua maior deposição de gordura, o que pode ser observado na Figura 9.

A proporção de músculos na carcaça tendeu a decrescer, como já foi comentado anteriormente, em fases mais avançadas da vida do animal, com a aceleração do desenvolvimento dos tecidos adiposos, que são mais tardios que os tecidos ósseo e muscular. Isso indica que os tecidos adiposos internos têm seu desenvolvimento acelerado, à medida que o peso do animal se eleva, em maior grau do que ocorre com a gordura externa.

Resultados concordantes foram observados por Jones et al. (1985), citados por FREITAS (1995), que, trabalhando com dois tipos de dieta (forragem e concentrado), observaram diferenças na composi-

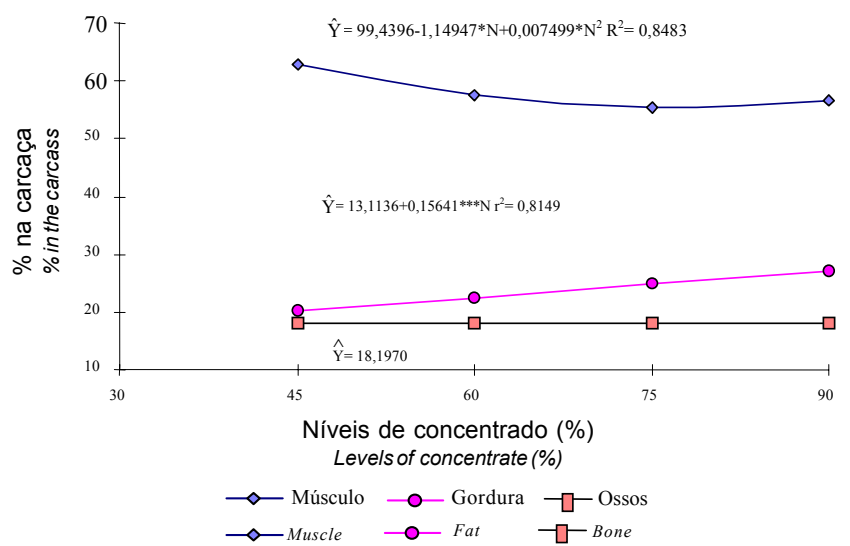

Figura 8 - Porcentagem de músculo, gordura e ossos na carcaça dos animais alimentados com dietas contendo diferentes níveis de concentrado.

Figure 8 - Percentage of muscles, fat and bones in the carcass of the animals fed diets containing various levels of concentrate.

ção corporal de novilhos. Animais que receberam dietas à base de concentrado (mais energéticas) apresentaram maiores teores de gordura na carcaça em relação aos que receberam rações à base de forragem.

As análises de regressão para relação músculo:osso das carcaças, por meio das quais foram obtidos resultados de 3,$38 ; 3,26 ; 2,89$; e $3,30 \%$, para os níveis de $45,60,75$ e $90 \%$ de concentrado nas dietas, respectivamente, não mostraram efeito significativo $(\mathrm{P}>0,05)$ do nível de concentrado das dietas.

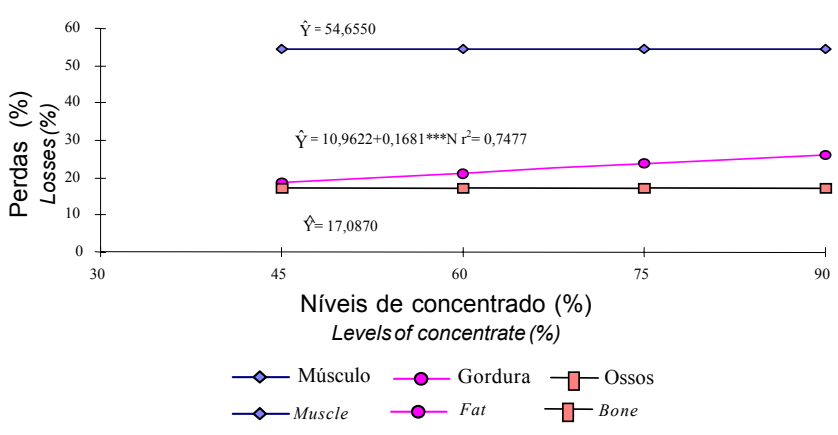

Figura 9 - Estimativa da quantidade de músculos, gordura e ossos nas carcaças de animais alimentados com dietas contendo diferentes níveis de concentrado.

Figure 9 - Estimate of quantity of muscles, fat and bones in the carcasses of the animals fed diets with different levels of concentrate.

Rev. bras. zootec., 30(6S):2154-2162, 2001 


\section{Conclusões}

O nível de concentrado da dieta influenciou positivamente o rendimento de carcaça, sendo que os animais alimentados com dietas contendo $90 \%$ de concentrado apresentaram melhores rendimentos, além de maiores teores de gordura.

Os resultados encontrados para o rendimento de carcaça, para todos os níveis de concentrado estudados, confirmam o potencial desses animais como produtores de carne, face ao seu ótimo desenvolvimento e à qualidade da carne produzida, indicando ser tecnicamente viável a possibilidade de exploração como produtores de carne.

\section{Referências Bibliográficas}

BERG, R.T., BUTTERFIELD, R.M. 1979 Nuevos conceptos sobre desarrollo de ganado vacuno. Zaragoza: Acribia. 297p.

BOER, T. Veal production in the European community. New trends in veal calf production. In: INTERNATIONAL SYMPOSIUM ON VEAL CALF PRODUCTION, 1990, Wageningen, Netherlands. Proceedings... Wageningen: EAAP Publication, 1991, n.52, p.8-15.

DODE, M.A.T., JARDIM, P.O.C., OSÓRIO, J.C.S. et al. 1986. Estimativas dos principais cortes e da porção comestível da carcaça, em novilhos Holandês PB. Pesq. Agropec. Bras., 21(1):771-776.

FIELD, R.A., SCHOONOVER, C.D. 1967. Equations for comparing Longissimus dorsi areas in bulls of different weights. J. Anim. Sci., 26(4):709-712.

GALVÃO, J.G.C., FONTES, C.A.A., PIRES, C.C. et al. 1991. Características e composição física da carcaça de bovinos não castrados, abatidos em 3 estágios de maturidade de três grupos raciais. R. Soc. Bras. Zootec., 20(5):502-512.

GONÇALVES, L.C. 1988. Digestibilidade, composição corporal, exigências nutricionais e características das carcaças de zebuinos, taurinos e bubalinos. Viçosa, MG: UFV, 1988. 238 p. Tese (Doutorado em Zootecnia) - Universidade Federal de Viçosa.

GRONEVELT, R. Veal production in North America. New trends in veal calf production. In: INTERNATIONAL SYMPOSIUM ON VEAL CALF PRODUCTION, 1990, Wageningen, Netherlands. Proceedings... Wageningen: EAAP Publication, 1991. n.52, p.16-19.

HANSKINS, O.G., HOWE, P.E. 1946. Estimation of the composition of beef carcasses and cuts local, USDA. (Tech. bulletin - USDA, 926).

JARDIM, P.O.C., ZIEGLER, J.C.S., OSÓRIO, J.C.S. 1985. Predição dos principais cortes da carcaça em novilhos. Pesq. Agropec. Bras., 20(2):253-258.

JORGE, A.M. Ganho de peso, conversão alimentar e características da carcaça de bovinos e bubalinos. Viçosa, MG: UFV, 1993. 97p. Dissertação (Mestrado em Zootecnia) Universidade Federal de Viçosa, 1993.
KEMPSTER, A.J., SOUTHGATE, J.R. 1984 Beef breed comparisons in the U.K. Livest. Prod. Sci., 11:491-501.

LANNA, D.P. Fatores condicionantes e predisponentes da puberdade e da idade de abate. Produção de novilho de corte. In: SIMPÓSIO SOBRE PECUÁRIA DE CORTE, 4, 1997, Piracicaba. Anais...Piracicaba, FEALQ, 1997. p.41-78.

LUCHIARI FILHO, A., ALLEN, D.M. 1982. Estimativas de características de carcaça usando medidas no animal vivo. Zootecnia, 20(2):75-88.

MARTINS, V.R.A. Utilização de dejetos de suínos em dietas de ovinos em sistema de confinamento. Lavras, MG, UFLA, 1997, 51p. Dissertação (Mestrado em Zootecnia) - Universidade Federal de Lavras, 1997.

MÜLLER, L. 1980. Normas para avaliação de carcaças e concurso de carcaças de novilhos e bois gordos. Santa Maria: Universidade Federal de Santa Maria. 31p.

NATIONAL RESEARCH COUNCIL - NRC.1988. Nutrient requirements of dairy cattle. Washington, D.C.: National Academic Press. 90p.

PEREZ REDONDO, F. 1990. Normas de alimentación para el cebo intensivo de terneros frisones. Bovis, 36:37-69.

PERON, J.A. 1991. Características e composição física e química, corporal e da carcaça de bovinos de cinco grupos genéticos, submetidos à alimentação restrita e "ad libitum". Viçosa, MG: UFV, 1991. 126p. Dissertação (Mestrado em Zootecnia) - Universidade Federal de Viçosa.

PRESTON, T.R., WILLIS, M.B. 1974. Intensive beef production. 2.ed. Oxford: Pergamon Press. 546p.

RESTLE, J. 1997. Confinamento de terneiros. In: RESTLE, J. (Ed.) Técnicas avançadas na recria e engorda de bovinos de corte. Santa Maria: Universidade Federal de Santa Maria. 67p.

TEIXEIRA, J.C. 1984. Exigências de energia e proteina, composição e área corporal e principais cortes da carcaça em seis grupos genéticos de bovídeos. Viçosa, MG: UFV, 1984, 94p. Tese (Doutorado em Zootecnia) - Universidade Federal de Viçosa.

UNIVERSIDADE FEDERAL DE VIÇOSA - UFV. 1995. SAEG (Sistema de Análises Estatísticas e Genéticas). Viçosa, MG (Versão 5.0).

UNITED STATES DEPARTMENT OF AGRICULTURE USDA, 1995. Milk production, dispositions and income, Livestock statistics. Washington, D.C.: U.S. Department of Agriculture.

VELLOSO, L., SILVA, L.R.M., BOIN, C. et al. 1975. Desenvolvimento de bovinos mestiços Holandeses inteiros e castrados, em regime de confinamento e as características das carcaças. Bol. Ind. Anim., 32(1):37-45.

Recebido em: 28/08/00 Aceito em: 19/05/01 